\title{
Using Moran's I and GIS to study the spatial pattern of forest litter carbon density in a subtropical region of southeastern China
}

\author{
W. J. Fu' ${ }^{1,2}$, P. K. Jiang ${ }^{2}$, G. M. Zhou ${ }^{2}$, and K. L. Zhao ${ }^{1,3}$ \\ ${ }^{1}$ State key laboratory breeding base of subtropical forest cultivation in Zhejiang Province, Zhejiang A \& F University, \\ Lin'an 311300, China \\ ${ }^{2}$ Zhejiang Provincial Key Laboratory of Carbon Cycling in Forest Ecosystems and Carbon Sequestration, Zhejiang A \& F \\ University, Lin'an 311300, China \\ ${ }^{3}$ School of Environmental and Resource Sciences, Zhejiang A\&F University, Lin'an 311300, China
}

Correspondence to: W. J. Fu (fuweijun@zafu.edu.cn), P. K. Jiang (jiangpeikun@zafu.edu.cn) and K. L. Zhao

(kelizhao@zafu.edu.cn)

Received: 13 October 2013 - Published in Biogeosciences Discuss.: 9 December 2013

Revised: 16 March 2014 - Accepted: 18 March 2014 - Published: 29 April 2014

\begin{abstract}
Spatial pattern information of carbon density in forest ecosystem including forest litter carbon (FLC) plays an important role in evaluating carbon sequestration potentials. The spatial variation of FLC density in the typical subtropical forests in southeastern China was investigated using Moran's I, geostatistics and a geographical information system (GIS). A total of 839 forest litter samples were collected based on a $12 \mathrm{~km}$ (south-north) $\times 6 \mathrm{~km}$ (east-west) grid system in Zhejiang province. Forest litter carbon density values were very variable, ranging from $10.2 \mathrm{~kg} \mathrm{ha}^{-1}$ to $8841.3 \mathrm{~kg} \mathrm{ha}^{-1}$, with an average of $1786.7 \mathrm{~kg} \mathrm{ha}^{-1}$. The aboveground biomass had the strongest positive correlation with FLC density, followed by forest age and elevation. Global Moran's I revealed that FLC density had significant positive spatial autocorrelation. Clear spatial patterns were observed using local Moran's I. A spherical model was chosen to fit the experimental semivariogram. The moderate "nugget-to-sill" (0.536) value revealed that both natural and anthropogenic factors played a key role in spatial heterogeneity of FLC density. High FLC density values were mainly distributed in northwestern and western part of Zhejiang province, which were related to adopting long-term policy of forest conservation in these areas, while Hang-Jia-Hu (HJH) Plain, Jin-Qu (JQ) Basin and coastal areas had low FLC density due to low forest coverage and intensive management of economic forests. These spatial patterns were in line with the spatial-cluster map described by local Moran's I. Therefore, Moran's I, combined with geo-
\end{abstract}

statistics and GIS, could be used to study spatial patterns of environmental variables related to forest ecosystem.

\section{Introduction}

Forest litter is the dead organic matter produced by aboveground plants in forest ecosystems, (Wang et al., 1989). It is one of the most important components of carbon and nutrient cycling, and regulates soil microclimate by forming a buffering interface between the soil surface and the atmosphere (Sayer, 2006). Zhou et al. (2000) reported that the carbon storage in forest litter should not be neglected as it is the third largest carbon pool in forest ecosystem. Generally the annual nutrients released from litter decomposition could meet $69-87 \%$ of total nutrients required for forest growth (Waring and Schlesinger, 1985). The amount of litter on the forest floor also affects soil nutrient status, soil water content, soil temperature, and $\mathrm{pH}$ (Sayer, 2006).

Global warming is now becoming a major concern in China and worldwide. Carbon sequestration is considered as an effective approach to deal with the increasing carbon dioxide $\left(\mathrm{CO}_{2}\right)$ concentration in atmosphere. Compared to the engineering technology (Matysek et al., 2005), forests as a cost-effective carbon sink play an important role by absorbing $\mathrm{CO}_{2}$ (Stern 2007). The Kyoto Protocol report under the United Nations Framework Convention on Climate Change (UNFCCC) requires that parties estimate the carbon stock 
not only in aboveground and belowground biomass, but also in litter and soil, separately (Takahashi et al., 2010).

Soil organic carbon, biomass carbon (aboveground and belowground biomass carbon), forest litter carbon, dead standing tree and fallen log (coarse woody debris) carbon were the four main carbon types in forest ecosystem (Lu et al., 2012). The forest litter (fallen leaves, twig, flower and fruit) forms a specific carbon pool, playing an important role between soil organic carbon and biomass carbon. It is influenced by forest types, site conditions and forest management options. Generally, forest litter with coniferous species accumulates a thicker organic layer than that with broad-leaved species (Berg and McClaugherty 2003). Compared to intensive management, moso bamboo forests have more litter fall under conventional management (Fu et al., 2014). Natural and anthropogenic disturbances, such as typhoons, ice storm and non-commercial thinning operations, result in an increase in the dead organic matter stock (Harmon et al., 1986; Xu et al., 2013).

Since the 1990s, the forest litter carbon (FLC) content has been sampled and measured based on traditional forest inventory system or long-term experimental forest plots (Matthew et al, 2011; Chang et al., 2007, Zhou et al., 2008), but little is known about the spatial distribution of FLC density at regional scale. This is now important as such information can be used to understand the forest resource status and variation, and guide sustainable development of forest.

Accurate assessment of the spatial patterns and stocks of forest litter carbon, especially at national and sub-national scales, is an indispensable step when evaluating sequestration potentials (Liu et al., 2011). To acquire accurate estimates of forest litter carbon, reliable data sets providing information on forest types of sites within the entire region are required, as FLC density varies from place to place, controlled by a series of environmental factors at different spatial scales (Sainju et al., 2008; Wang et al., 2009). Over the last 30 years, geostatistical methods like semivariogram and kriging have been successfully used to investigate the spatial variability of continuously varying environmental parameters and to incorporate this information into mapping process (Burrough and McDonnell, 1998). Geostatistics combined with other spatial statistics in exploratory spatial data analysis (ESDA) can identify and describe the locations, magnitudes and shapes of statistically significant patterns in a study area. Spatial-cluster analysis played an important part in the ESDA and in the construction of spatial models (Jacquez, 2007). Compared to Getis's G index (Getis and Ord, 1992), Geary's C index (Geary, 1954) and Tango's C index (Tango, 1995), the Moran's I (Anselin, 1995) seems to be a very popular method in spatial-cluster analysis in recent studies. To better understand the FLC reservoir, it is necessary to update regional FLC information with intensive sampling and to apply spatial analysis methods to produce an integrated distribution map. The main objectives of this study were (a) to characterize the spatial variability of FLC density in sub- tropical forest in eastern China and (b) to analyze the spatial patterns of FLC density and the corresponding environmental factors.

\section{Materials and methods}

\subsection{Study area and sampling site description}

This study was carried out in a typical subtropical region of Zhejiang province, China (Fig. 1). Zhejiang covers an area of $101800 \mathrm{~km}^{2}\left(118^{\circ} 01^{\prime}\right.$ to $123^{\circ} 10^{\prime} \mathrm{E}, 27^{\circ} 06^{\prime}$ to $\left.31^{\circ} 11^{\prime} \mathrm{N}\right)$, with a population of 54.4 million. It has a subtropical marine monsoon climate with an average annual rainfall of $1490 \mathrm{~mm}$ and mean annual temperature of $16.5^{\circ} \mathrm{C}$. The main soil type is red soil (Ferralic Cambisol; FAO 2006). From southwest to northeast, the elevation gradually decreases from $1603 \mathrm{~m}$ to $10 \mathrm{~m}$. The total area of forest is approximately $58442 \mathrm{~km}^{2}$, accounting for $57.4 \%$ of total land area in Zhejiang province (Zhejiang Forestry Bureau, 2006). The main forest types include evergreen broad-leaved forest, bamboo and other types (such as economic forest) (Yuan et al., 2009).

In 2010, a total of 839 forest litter samples were collected from fixed forest plots based on a $12 \mathrm{~km}$ (southnorth) $\times 6 \mathrm{~km}$ (east-west) grid system (Fig. 1). Each sample was the composite of at least three sub-samples of a $100 \mathrm{~cm} \times 100 \mathrm{~cm}$ plot randomly distributed in the fixed forest plots. The longitudes and latitudes of the sampling points were recorded using a portable global positioning system (GPS) receiver. The distribution of sample locations in the study area is shown in Fig. 1. Meanwhile, the basic information such as forest type, forest age, elevation, grass and bush coverage, and so on was also investigated in order to better understand the spatial variation of forest litter carbon density.

\subsection{Forest litter treatment}

Forest litter samples were transported to the laboratory and then dried in the oven at a temperature of $105^{\circ} \mathrm{C}$. All the samples were grounded, and $0.5 \mathrm{~g}$ per sample was taken for laboratory analysis. The content of forest litter carbon was determined by organic element analyzer (Vario Max CN). Forest litter carbon density was calculated using the following formula:

$Y=10000 \times a \times X / 3$,

$Z=b \times Y$,

where $Y$ represents the dry weight of forest litter on unit area of forest (in $\mathrm{kg} \mathrm{ha}^{-1}$ ), $a$ represents the percentage of dry weight, $X$ is the total fresh weight of three sub-samples (in $\mathrm{kg}), b$ is the carbon content determined by organic element analyzer, $Z$ is forest litter carbon density (in $\mathrm{kg} \mathrm{ha}^{-1}$ ). 


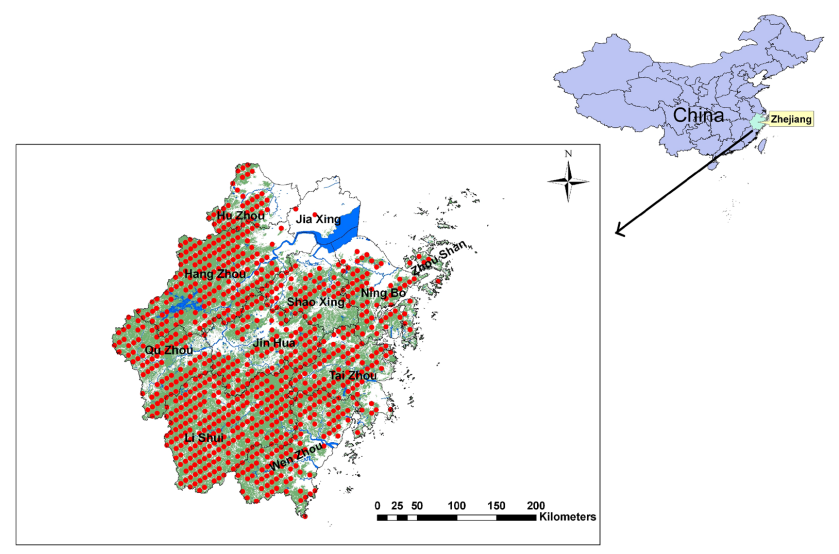

Fig. 1. Location of the study area and samples.

\subsection{Spatial autocorrelation analyses}

Moran's I is a commonly used indicator of spatial autocorrelation. In this study, global Moran's I (Moran 1950) was used as the first measure of spatial autocorrelation. Its values range from -1 to 1 . The value " 1 " means perfect positive spatial autocorrelation (high values or low values cluster together), while "-1" suggests perfect negative spatial autocorrelation (a checkerboard pattern), and " 0 " implies perfect spatial randomness (Tu and Xia, 2008).

While global Moran's I quantifies the spatial autocorrelation as a whole, the local indicators of spatial association (LISA) measure the degree of spatial autocorrelation at each specific location (Anselin, 1995) by using local Moran's I. It is also good for identifying local spatial cluster patterns and spatial outliers (Harries, 2006). Local Moran's I index (Levine, 2004) can be expressed as

$I_{i}=\frac{z_{i}-\bar{z}}{\sigma^{2}} \sum_{j=1, j \neq i}^{n}\left[W_{i j}\left(z_{j}-\bar{z}\right)\right]$,

where $\bar{z}$ is the mean value of $z$ with the sample number of $n ; z_{i}$ is the value of the variable at location $i ; z_{j}$ is the value at other locations (where $j \neq i$ ); $\sigma^{2}$ is the variance of $z$; and $W_{i j}$ is a distance weighting between $z_{i}$ and $z_{j}$, which can be defined as the inverse of the distance. The weight $W_{i j}$ can also be determined using a distance band: samples within a distance band are given the same weight, while those outside the distance band are given the weight of 0 .

The results of local Moran's I index can be standardized, so its significance level can be tested based on an assumption of a normal distribution (Levine 2004). When using local Moran's I index to analyze the spatial pattern, the results were affected by the definition of weight function, data transformation, and existence of extreme values (Zhang et al. 2008). These factors were taken into consideration in order to obtain reliable and stable results. For the definition of weight function, the best distance band was obtained based on the largest global Moran's I value, indicating the strongest spatial autocorrelation of FLC density. In this study, this distance band was $36 \mathrm{~km}$, which was further used to study spatial clusters. Given the non-normality of the data, a Box-Cox transformation (Box and Cox, 1962) was used to define the appropriate exponent to use for transforming the data to a normal distribution. The transformed data can also eliminate the effect of extreme values on the spatial clusters analysis.

A high positive local Moran's I value implies the target value is similar to its neighborhood, and then the locations are spatial clusters, which include high-high clusters (high values in a high value neighborhood) and low-low clusters (low values in a low value neighborhood). Meanwhile, a high negative local Moran's I value implies a potential spatial outlier, which is obviously different from the values of its surrounding locations. Spatial outliers include high-low (a high value in a low value neighborhood) and low-high (a low value in a high value neighborhood) outliers.

\subsection{Geostatistics analysis}

Geostatistics uses the techniques of variogram (or semivariogram) to measure the spatial variability of a regionalized variable, and provides the input parameters for the spatial interpolation of kriging (Goovaerts, 1997; Webster and Oliver, 2001). The semivariogram can be expressed as

$\gamma(h)=\frac{1}{2} E[z(x)-z(x+h)]^{2}$.

The usual computing equation for the variogram is

$\gamma(h)=\frac{1}{2 N(h)} \sum_{i=1}^{N(h)}\left[z\left(x_{i}\right)-z\left(x_{i}+h\right)\right]^{2}$,

where $\gamma(h)$ is the semivariance at a given distance $h ; z\left(x_{i}\right)$ is the value of the variable $Z$ at location of $x_{i}, h$ is the lag distance, and $N(h)$ is the number of pairs of sample points separated by $h$.

With the increase of distance, if the variogram stabilizes, it reaches a sill $\left(C+C_{0}\right)$. The distance at which the variogram reaches the sill is called the range $(a)$. Beyond this distance, data are considered to be independent. Discontinuities at the variogram origin could be present; such an unstructured component of variation at $h=0$ is known as nugget effect $\left(C_{0}\right)$, which may be due to sampling errors and short-scale variability (Pilar et al., 2006).

A variogram plot is obtained by calculating values of the variogram at different lag distances. These values are usually fitted with a theoretical model, such as spherical and exponential models. The fitted model provides information about the spatial structure as well as the input parameters for kriging.

Among the estimation methods, kriging is the most popular one, which "is a collection of generalized linear regression techniques for minimizing and estimating variance defined from a prior model for a covariance" (Olea, 1991). It is 
a type of weighted moving average:

$\hat{z}\left(x_{0}\right)=\sum_{i=1}^{n} \lambda_{i} z\left(x_{i}\right)$

where $\hat{z}\left(x_{0}\right)$ is the value to be estimated at the location of $x_{0} ; z\left(x_{i}\right)$ is the known value at the sampling site $x_{i}$, and $\lambda_{i}$ is a weighting coefficient. There are $n$ sites within the search neighborhood around $x_{0}$ used for the estimation, and the magnitude of $n$ will depend on the size of the moving search window and user definition.

The kriging estimates can be mapped, to reveal the overall trend of the data (Burgos et al., 2006). Maps provide useful visual displays of the spatial variability and can be used to represent and summarize environmental variables (Goodchild et al., 1993).

\subsection{Data analysis with computer software}

In the linear geostatistics method, a normal distribution for the studied variable is desired (Webster and Oliver, 2001). In this study, a statistical test of the Kolmogorov-Smirnov (KS) method together with skewness and kurtosis values was applied to evaluate the normality of data sets. Box-Cox transformation was performed by SAS software (version 9.1).

The descriptive parameters were calculated using SPSS ${ }^{\circledR}$ for windows (version 18.0). Global Moran's I and local Moran's I values were measured using software GeoDa (version 0.95i, Spatial Analysis Laboratory, 2007). The geostatistical analysis was carried out with VARIOWIN (version2.2). All maps were produced using GIS software $\operatorname{ArcMap}^{\circledR}$ (version 9.2).

\section{Results and discussion}

\subsection{Spatial symbol map of forest litter carbon density}

A point-symbol map of FLC density for the study area is shown in Fig. $2(n=839)$. The majority of FLC density values ranged from 1000.0 to $3000.0 \mathrm{~kg} \mathrm{ha}^{-1}$. Some high FLC density values were observed on the north-western and western parts of the study area, which were probably related to the adopting long-term policy of forest conservation in these areas. Low values were located in the middle part of Zhejiang province. This is mainly related to the intensive management by man, as the main forest type is economic forests, such as moso bamboo (Phyllostachys pubescens, Mazel ex Houzeau de Lehaie), Chinese chestnut (Castanea mollissima) and hickory (Carya cathayensis Sarg) forests. Intensive management referring to deep plow, annual fertilization, complete clearing of ground vegetation is carried out in order to improve fruit production. There were a number of scattered high FLC density values surrounded by relatively low values or low FLC density values surrounded by high values on the map, indicating the presence of spatial outliers.

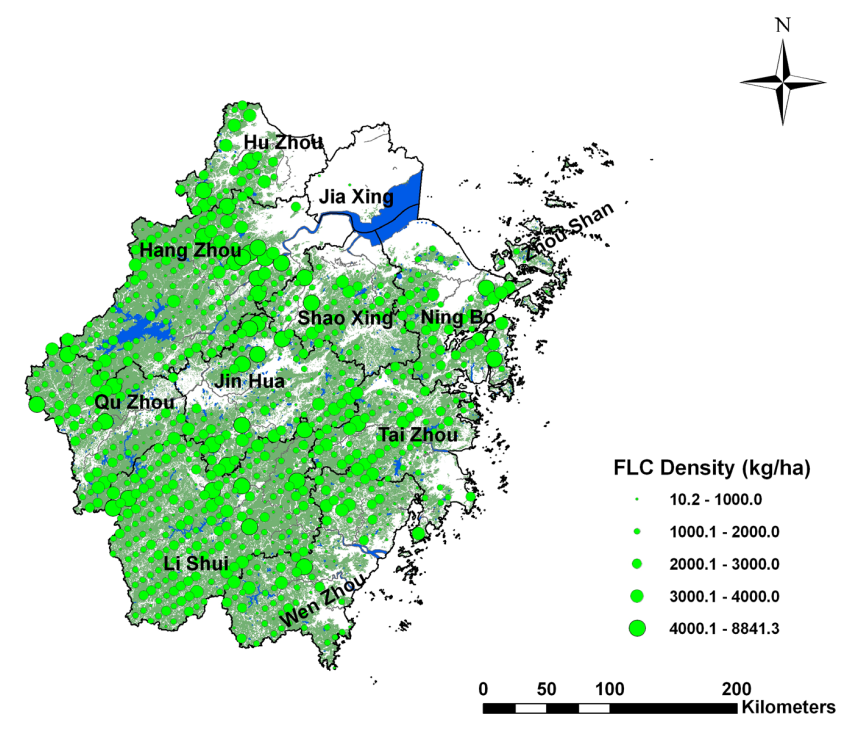

Fig. 2. Symbol map of FLC density values in Zhejiang province

\subsection{Descriptive statistics for forest litter carbon density}

The commonly used descriptive parameters were calculated (Table 1). Forest litter carbon density values were very variable, ranging from $10.2 \mathrm{~kg} \mathrm{ha}^{-1}$ to $8841.3 \mathrm{~kg} \mathrm{ha}^{-1}$, with an average of $1786.7 \mathrm{~kg} \mathrm{ha}^{-1}$. The average FLC density value was much lower than that calculated by Fang and Chen (2001) and Li et al. (2011). This was mainly related to the forest age in Zhejiang province, as most of forest trees were planted after 1978 (Zhang et al., 2012). The maximum and $95 \%$ percentile of the data were much higher than the upper quartile $(75 \%)$, indicating positive skewed distribution, which was confirmed by the large positive skewness (1.76) and kurtosis (5.40) values. The CV value is the most discriminating factor for describing variability; when $\mathrm{CV}$ is less than $10 \%$, it shows small variability; while $\mathrm{CV}$ is more than $90 \%$, it shows extensive variability (Zhang et al., 2007). In our study, the CV value of FLC density was $66.69 \%$, indicating moderate variability in Zhejiang province.

Histograms of FLC density with a normal distribution curve are shown in Fig. 2. The raw data have a long tail towards higher FLC density values (Fig. 3a). Other studies have also shown that environmental variables are often skewed from a normal distribution towards positive values because of the relatively smaller percentage of high values (Chang et al., 2003). The Box-Cox transformed data show a normal distribution (Fig. 3b). This is confirmed by the $\mathrm{K}-\mathrm{S}$ $p$ value ( $>0.05)$. Therefore, transformed data were used for geostatistical analysis. 
Table 1. Descriptive statistics* of forest litter carbon density $\left(\mathrm{kg} \mathrm{ha}^{-1}\right)$.

\begin{tabular}{ccccccccccccc}
\hline Min & $5 \%$ & $25 \%$ & Median & $75 \%$ & $95 \%$ & Max & Mean & SD & CV $(\%)$ & Skew & Kurt & K-S $p$ \\
\hline 10.2 & 325.4 & 1045.2 & 1601.1 & 2207.8 & 5578.4 & 8841.3 & 1786.7 & 1191.6 & 66.69 & $1.76(0.02)$ & $5.40(0.34)$ & $0.00(0.053)$ \\
\hline
\end{tabular}

* Min, minimum; Max, maximum; SD, standard deviation; CV, coefficient of variation; Skew, skewness, Kurt, kurtosis; K-S $p$, significance level of Kolmogorov-Smirnov test for normality.

Skew, Kurt and $\mathrm{K}-\mathrm{S}_{p}$ values in brackets were calculated after Box-Cox transformation.
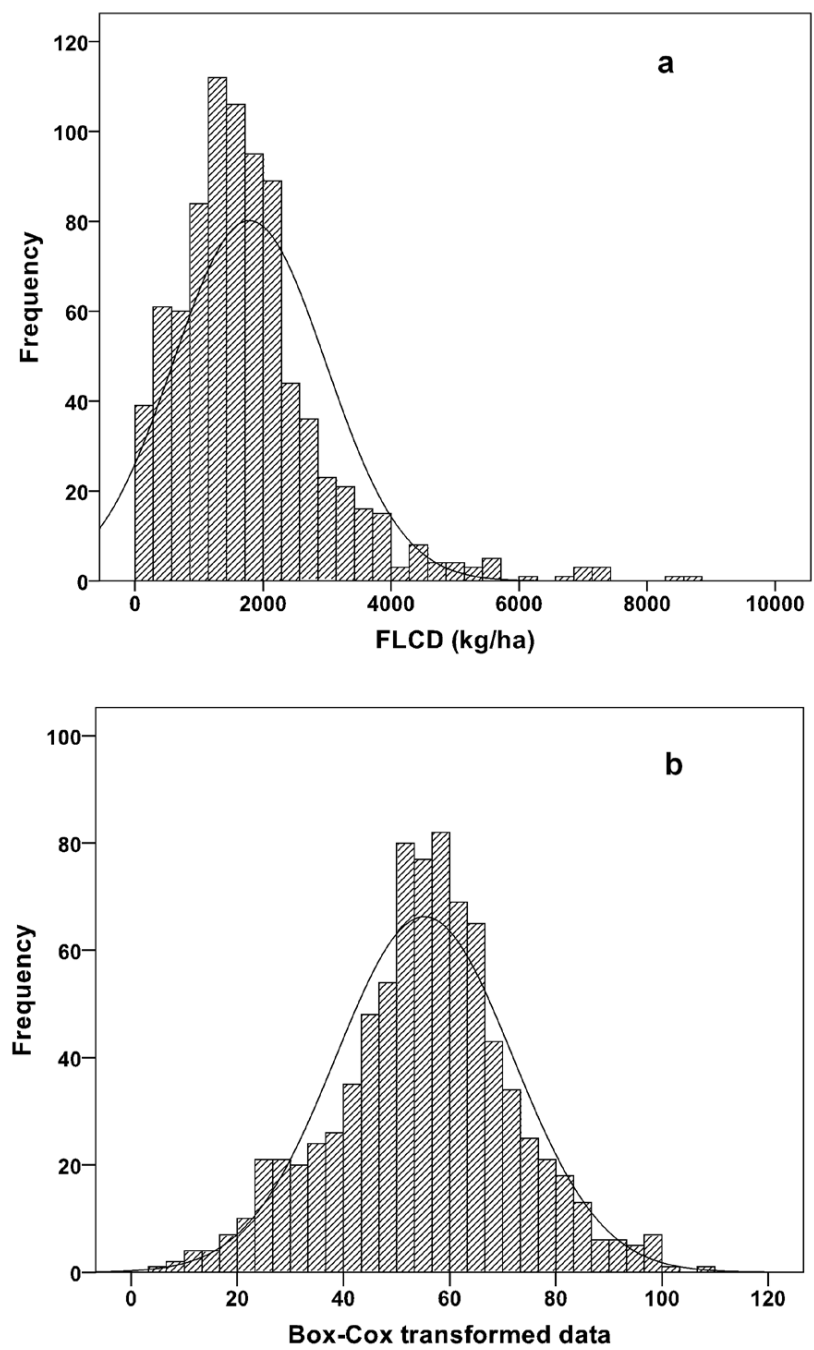

Fig. 3. Histograms of FLC density: (a) raw data and (b) Box-Cox transformed data.

\subsection{The environmental factors related to forest litter carbon density}

Spearman correlation coefficients between FLC density and other environmental factors were calculated (Table 2). Positive and significant correlations between FLC density and elevation, shrub coverage, average shrub height, forest age, and aboveground biomass were found, while negative and
Table 2. Spearman correlation coefficients between forest litter carbon density and other variables.

\begin{tabular}{lr}
\hline Variables $^{\mathrm{a}}$ & $r$ \\
\hline Elevation & $0.188^{\mathrm{b}}$ \\
Slope aspect & $-0.072^{\mathrm{a}}$ \\
Slope position & $-0.185^{\mathrm{b}}$ \\
Shrub coverage & $0.077^{\mathrm{a}}$ \\
Average shrub height & $0.196^{\mathrm{b}}$ \\
Herb coverage & $-0.156^{\mathrm{b}}$ \\
Average herb height & 0.034 \\
Forest age & $0.223^{\mathrm{b}}$ \\
Aboveground biomass & $0.306^{\mathrm{b}}$ \\
\hline a Correlation is significant at the 0.01 level. \\
b Correlation is significant at the 0.05 level.
\end{tabular}

significant correlations between FLC density and slope aspect, slope position, and herb coverage were observed.

Zhang et al. (2013) reported that the FLC density values increased with the increasing elevation in subtropical forest in China. In contrast, other studies indicated that FLC density decreased with the increasing elevation in forests of China (Ling et al., 2009) due to large elevation difference. The vertical distribution of FLC density was mainly influenced by the variation of the combination of water and heat (Cao et al., 2010). The positive correlation between FLC density and elevation in this study was probably related to the specific geographical location of Zhejiang province in China (Fig. 1). It has relatively low elevations, high rainfall and moderate annual temperature, which are suitable for plant growth across the whole area.

The aboveground biomass had the strongest correlation with FLC density, indicating that the aboveground vegetation was the main source of forest litter carbon. The FLC density values in typical forest types were studied (Fig. 4). The broad-leaved forest had the highest FLC density, followed by mixed coniferous broad-leaved forest and coniferous forest. This finding was in line with another study (Huang et al., 2005). Meanwhile, moso bamboo forest and economic forest had relatively low FLC density values. This was due to the intensive management in the moso bamboo and economic forests, as local farmers cleared the forest litter. 


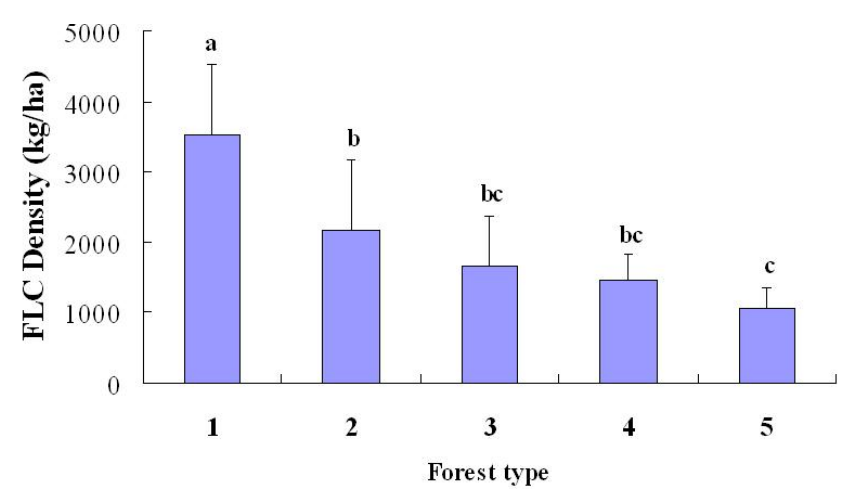

Fig. 4. FLC density under typical forest types in Zhejiang province: (1) broad-leaved forest, (2) mixed coniferous broad-leaved forest, (3) coniferous forest, (4) moso bamboo forest, and (5) economic forest. Different letters mean significantly different at 0.05 level.

\subsection{Spatial-cluster and spatial-outlier analyses}

GIS mapping techniques can help to identify spatial patterns visually, but not statistically (Zhang et al., 2008). The general spatial variations identified visually based on raw data in Fig. 2 can be statistically supported using local Moran's I testing. The results of the global Moran's I and LISA analysis are illustrated in Fig. 5. Significant positive spatial autocorrelation (Moran's $\mathrm{I}=0.112, p<0.05$ ) was observed for FLC density, revealing the existence of potential spatial patterns in their spatial distribution (Fu et al., 2010).

A large high-high spatial cluster was observed in the north-western part of Zhejiang province, mainly on the Tianmu Mountain area, which is famous as the main natural conservation area in China. Relative small high-high spatialcluster areas were located in the southwest to northeast direction across the Zhejiang province, while some low-low spatial clusters were found in the middle part and southeastern coastal area of study area. Most of the high-low outliers were close to the low-low area, as these samples had much higher FLC density values than those in the neighborhood. On the other hand, the low-high outliers were mainly located closely to the high-high spatial-cluster area. It should be noticed that the local Moran's I index is sensitive to outliers (Fu et al., 2011). A total of 33 spatial outliers were detected.

\subsection{Semivariance analysis and spatial distribution}

To stabilize the spatial variance, the transformed data, excluding the spatial outliers, were used. There was no evident anisotropy in the variogram for Box-Cox transformed data, implying that the FLC density values varied similarly in all directions of the study area and the semivariance depended only on the distance between samples (Andronikov et al., 2000). The best fitted variogram model for FLC density was a spherical model (Fig. 6). The range value was $42.43 \mathrm{~km}$, indicating that current sampling density was enough to study

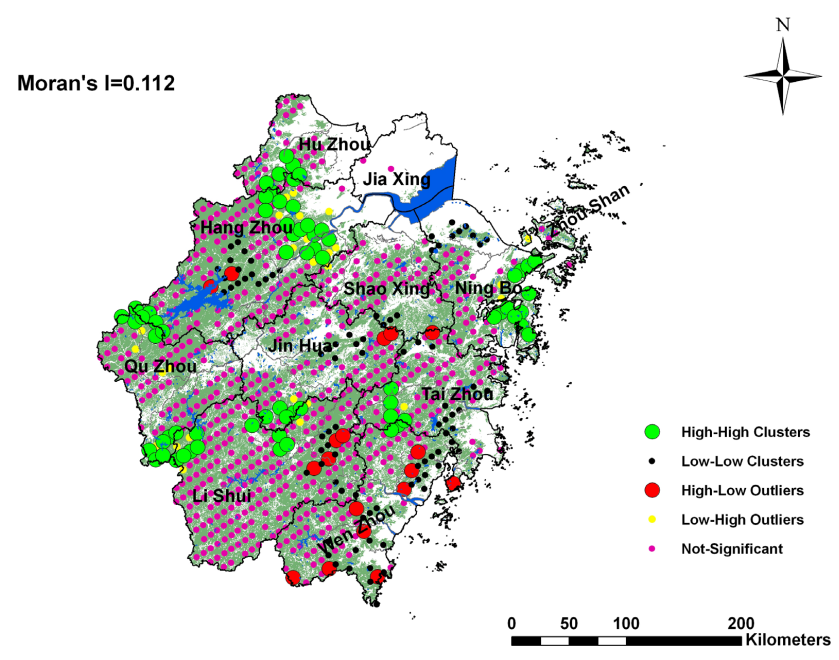

Fig. 5. Spatial clusters and spatial outliers map of FLC density.

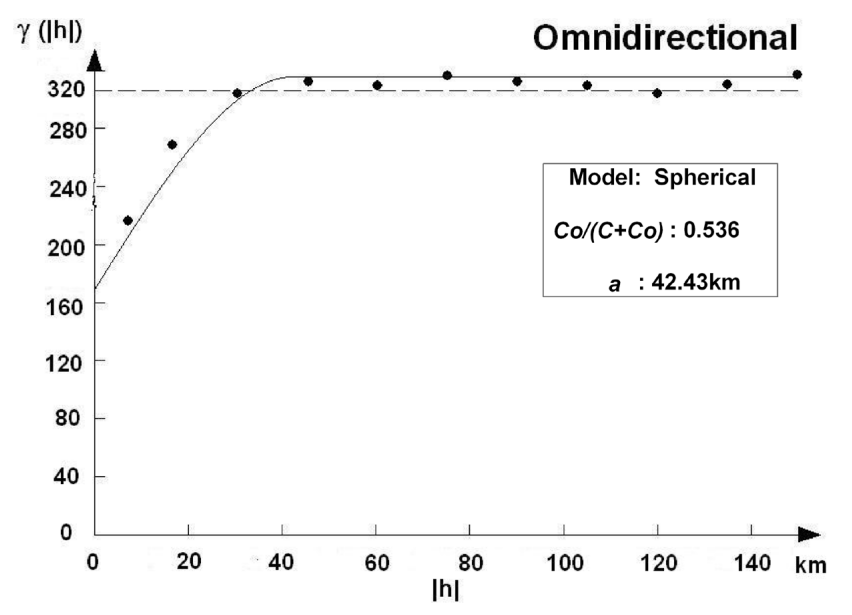

Fig. 6. Empirical semivariogram (dots) and the fitted model (line) of Box-Cox transformed data.

the spatial structure of FLC density in Zhejiang province. But more samples were necessary to reveal local spatial variation of FLC density in forest, using complex geostatistical analysis such as regression kriging ( $\mathrm{Li}$ 2010). The "nugget-to-sill" value was 0.536 . As a rough guideline, the variable is considered to have a strong spatial dependence if the "nuggetto-sill" value is $<0.25$, a moderate spatial dependence if this ratio is between 0.25 and 0.75 , and a weak spatial dependence if the ratio is $>0.75$ (Cambardella et al., 1994). Variables that are strongly spatially dependent are controlled by intrinsic factors such as soil texture, while weak spatial dependence may be controlled by extrinsic factors such as land management (Sadeghi et al., 2006). The variable in this study was moderately spatially dependent, indicating that both intrinsic and extrinsic factors influence the spatial dependence of FLC density. 


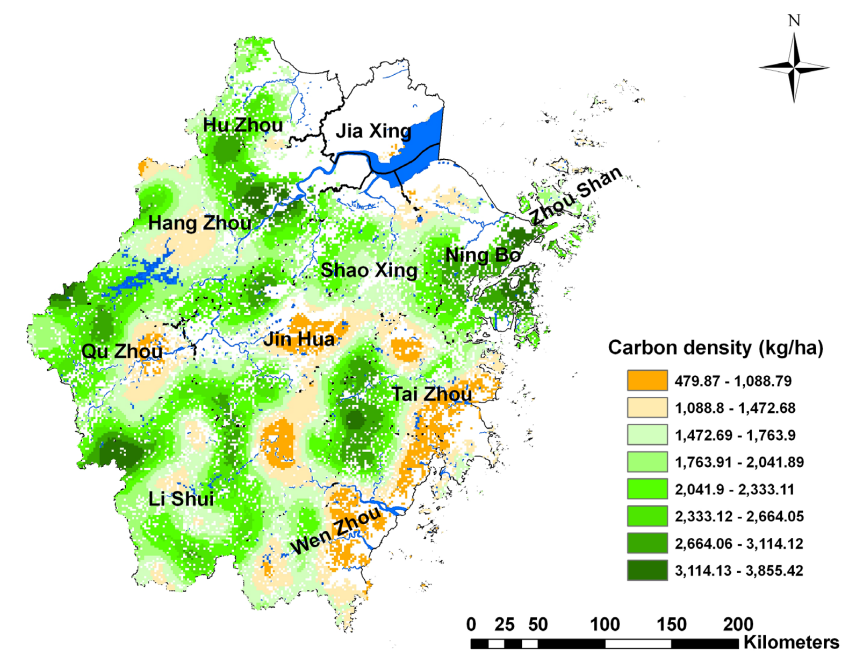

Fig. 7. Spatial distribution map of FLC density.

For the spatial interpolation, a cell size of $0.5 \mathrm{~km} \times 0.5 \mathrm{~km}$ was chosen to divide the study area into a grid system of 712 columns (E-W direction) and 843 rows ( $\mathrm{N}-\mathrm{S}$ direction). The number of search neighborhood was set to 18 , as no clear improvement was found when more values were used. The chosen cell size was regarded as being effective to show the spatial patterns of the variable. The Box-Cox transformed data were used for interpolation, and the corresponding kriging method is called trans-Gaussian kriging (Cressie, 1993). The results are shown in Fig. 7.

In the northwestern part of Zhejiang province, the FLC density values ranged from 2600 to $3855 \mathrm{~kg} \mathrm{ha}^{-1}$, which were much higher than other areas, while the FLC density was very low in the northern part of study area, as this area is called Hang-Jia-Hu (HJH) Plain with little forest. According to the Zhejiang forest inventory report (2006), the forest area only accounted for $9.18 \%$ of the HJH Plain area. In the middle part of Zhejiang province (Jin-Qu Basin), the FLC values ranged from 479 to $2000 \mathrm{~kg} \mathrm{ha}^{-1}$. The relatively low FLC values were mainly due to the land management in this area. Jin-Qu Basin is the main commercial grain base. The main forest type is economic forest, which is influenced by human activities. The relatively high FLC values in the WenzhouTaizhou boundary were related to the Yandang Mountains, which is a famous tourist area. The forest is well protected in this area, while low FLC values were located in the coastal part of southern Zhejiang. The low forest biomass, due to typhoon, climate and human disturbance, resulted in the low forest litter (Huang et al., 2005). These high and low value patterns were in line with the above spatial clusters revealed by local Moran's.

\section{Conclusions}

The average FLC density was $1786.7 \mathrm{~kg} \mathrm{ha}^{-1}$ in this study. Elevation, forest age and aboveground vegetation were significantly correlated with FLC density. Compared to other typical subtropical forest types, broad-leaved forest had the highest average FLC density, while economical forest had the lowest FLC density. Forest management played an important role in the carbon storage of forest litter.

Moderate spatial dependency was found for FLC density. The spatial variation of FLC density was related to natural and anthropogenic factors. The spatial patterns were in line with the spatial clusters. The methodology used in this study could provide guidance for studying spatial patterns of environmental variables in forest ecosystem.

Acknowledgements. This work was financially supported by Zhejiang provincial priority first-level discipline of forestry open funded projects (KF201333), the National Natural Science Foundation of China (no. 41201538, 41201323), and the Key Science and Technology Innovative Group of Zhejiang province (2010R50030).

Edited by: F. Carswell

\section{References}

Andronikov, S. V., Davidson, D. A., and Spiers, R. B.: Variability incontamination by heavy metals: sampling implications, Water Air Soil Pollut., 120, 29-45, 2000.

Anselin, L.: Local indicators of spatial association - LISA. Geogr. Anal., 27, 93-115, 1995.

Berg, B. and McClaugherty, C.: Plant Litter - Decomposition, Humus Formation, Carbon Sequestration. Springer-Verlag,Berlin Heidelberg, 2003.

Box G. E. P. and Cox D. R. An analysis of transformations, J. Royal Stat. Soc. B, 26, 211-252, 1962.

Burgos, P., Madejón, E., Pérez-de-Mora, A., and Cabrera, F.: Spatial variability of the chemical characteristics of a trace-elementcontaminated soil before and after remediation, Geoderma, 130, 157-175, 2006.

Burrough, P. A. and McDonnell, R. A.: Principles of Geographical information systems, Oxford University Press, Oxford, 1998.

Cambardella, C. A,, Moorman, A. T., Novak, J. M., Parkin, T. B., Karlen, D. L., Turco, R. F., and Konopka, A. E.: Field-scale variability of soil properties in central Iowa soils, Soil Sci. Soc. Am. J., 58, 1501-1511, 1994.

Cao, F. Q., Liu, C. H., Liu, M., and Cui, J. F.: Guangxi agricultural Sciences, G. X. Agric. Sci., 41, 693-697, 2010 (in Chinese).

Chang, J., Clay, D. E., Carlson, C. G., Clay, S. A, Malo, D. D., Berg, R., Kleinjan, J., and Wiebold, W.: Different techniques to identify management zones impact nitrogen and phosphorus sampling variability, Agron. J., 95, 1550-1559, 2003.

Cressie, N.: Statistics for spatial data (revised edition) John Wiley, New York, 1993.

Fang, J. Y. and Chen, A. P.: Dynamic forest biomass carbon pools in China and their significance, Acta Bot. Sin., 43, 967-973, 2001 (in Chinese). 
FAO: Global forest resource assessment, 2005, Food and Agricultural Organization of the United Nations, Rome, 2006.

Fu, W. J, Zhao, K. L., Zhang, C. S., and Tunney, H.: Spatial variation of soil test phosphorus in a long-term grazed experimental grassland field, J. Plant Nutr. Soil Sci., 173, 323-331, 2010.

Fu, W. J., Zhao, K. L., Zhang, C. S., and Tunney, H.: Using Moran's I and geostatistics to identify spatial patterns of soil nutrients in two different long-term phosphorus-application plots, J. Plant Nutri. Soil Sci., 174, 785-798, 2011.

Fu, W. J., Jiang, P. K., Zhao, K. L., Zhou, G. M., Li, Y. F., Wu, J. S., and $\mathrm{Du}, \mathrm{H}$. Q.: The carbon storage in moso bamboo plantation and its spatial variation in Anji County of southeastern China, J. Soil Sediment, 14, 320-329, 2014.

Geary, R. C.: The contiguity ratio and statistical mapping, Incorporated Statistician, 115-145, 1954.

Getis, A. and Ord, J. K.: The analysis of spatial association by use of distance statistics, Geogr. Anal., 24, 189-206, 1992.

Goodchild, M. F., Parks, B. O., and Steyaret, L. T.: Environmental Modelling with GIS, Oxford University Press, USA, 1993.

Goovaerts, P.: Geostatistics for natural resources evaluation, Oxford University Press, New York, 1997.

Harmon, M. E., Franklin, J. F., Swanson, F. J., Sollins, P., Gregory, S. V., Lattin, J. D., Anderson, N. H., Cline, S. P., Aumen, N. G., Sedell, J. R., Lienkaemper, G. W., Cromack Jr., K., and Cummins, K. W.: Ecology of coarse woody debris in temperate ecosystems, Adv. Ecol. Res., 15, 133-302, 1986.

Harries, K.: Extreme spatial variations in crime density in Baltimore County, MD, Geoforum, 37, 404-406, 2006

Huang, C. C., Ge, Y., Zhu, J. R., Yuan, W. G., Qi, L. Z., Jiang, B., Shen, Q., and Chang, J.: The litter of Pinus massoniana ecological public-welfare forest in Zhejiang Province and its relationship with the community characters, Acta Ecol. Sin., 25, 25072513, 2005

Jacquez, G. M.: The Handbook of Geographic Information Science: Spatial Cluster Analysis, Wiley-Blackwell, 2007.

Kerry, R. and Oliver, M. A.: Comparing sampling needs for variograms of soil properties computed by the method of moments and residual maximum likelihood, Geoderma, 140, 383-396, 2007.

Levine, N.: CrimeStat III: a spatial statistics program for the analysis of crime incident locations. Ned Levine \& Associates, Houston, TX., and the National Institute of Justice, Washington, DC, 2004.

Li, H. K., Lei, Y. C., and Zeng, W. S.: Forest carbon storage in china estimated using forestry inventory data, Sci. Silvae Sinicae, 47, 7-12, 2011 (in Chinese).

Li, Y.: Can the spatial prediction of soil organic matter contents at various sampling scales be improved by using regression kriging with auxiliary information?, Geoderma, 159, 63-75, 2010

Ling, H., Chen, G. S., and Chen, Z. Q.: The impact factors on forest litter of Chinese forest, J. Subtropical Resour. Environ. 4, 66-71, 2009( in Chinese).

Liu, Z. P., Shao, M. A., and Wang, Y. Q.: Effect of environmental factors on regional soil organic carbon stocks across the Loess Plateau region, China, Agr. Ecosys. Environ. 142, 184194, 2011.

Lu, Q. L., Wang, G. B., Yang, P., Zhang, A. B., and Ruan, H. H.: A review on the estimation methods of carbon pools of forest ecosystems, J. Nanjing Forestry University (Natural Science Edition), 36, 155-160, 2012.

Matthew, P., Randall, K., Brian, P., Rachel, M., and Martin, J.: Long-term management impacts on carbon storage in Lake States forests, Forest Ecol. Manag., 262, 424-431, 2011.

Matysek, A., Ford, M., Jakeman, G., Curtotti, R., Schneider, K., Aham-mad H., and Fisher B. S.: Near Zero Emissions Technologies, ABARE eReport 05.1. Canberra, Australian Bureau of Agri-cultural and Resource Economics, 2005.

Moran, P. A. P.: Notes on continuous stochastic phenomena, Biometrika, 37, 17-23, 1950.

Olea, R. A.: Geostatistical Glossary and Multilingual Dictionary. Oxford University Press, New York, USA, 1991.

Pilar, B., Engracia, M., Alfredo, P. M., and Francisco, C.: Spatial variability of the chemical characteristics of a trace-elementcontaminated soil before and after remediation, Geoderma, 130, 157-175, 2006.

Sadeghi, A., Graff, C. D., Starr, J., Mccarty, G., Codling, E., and Sefton, K.: Spatial variability of soil phosphorous levels before and after poultry litter application, Soil Sci., 171, 850-857, 2006.

Sainju, U. M., Senwo, Z. N., Nyakatawa, E. Z., Tazisong, I. A., and Reddy, K. C.: Soil carbon and nitrogen sequestration as affected by long-term tillage, cropping systems, and nitrogen fertilizer sources, Agr. Ecosyst. Environ., 127, 234-240, 2008

Sayer, E. J.: Using experimental manipulation to assess the roles of leaf litter in the functioning of forest ecosystems, Biol. Rev., 81, 1-31, 2006.

Stern, N.: The Economics of Climate Change: The Stern Review, Cambridge University Press, UK ISBN-13: 9780521700801, 2007.

Sundarapandian, S. M. and Swamy, P. S.: Litter production and leaflitter decomposition of selected tree species in tropical forests at Kodayar in the Western Ghats, India Forest Ecol. Manag., 123, 231-234, 1999.

Takahashi, M., Ishizuka, S., Ugawa, S., Sakai, Y., Sakai, H., Ono, K., Hashimoto, S., Matsuura, Y., and Morisada, K.: Carbon stock in litter, deadwood and soil in Japan's forest sector and its comparison with carbon stock in agricultural soils, Soil Sci. Plant Nutr., 56, 19-30, 2010.

Tango, T.: A class of test for detecting "general" and "focused" clustering of rare disease, Stat. Med., 14, 2323-2334, 1995.

Tu, J. and Xia, Z. G.: Examining spatially varying relationships between land use and water quality using geographically weighted regression I: Model design and evaluation, Sci Total Environ., 407, 358-378, 2008.

Wang, F. Y.: Research on forest litter production, Adv. Ecol., 6, 8298, 1989 (in Chinese).

Wang, Y. Q., Zhang, X. C., Zhang, J. L., and Li, S. J.: Spatial variability of soil organic carbon in a watershed on the Loess Plateau, Pedosphere, 19, 486-495, 2009.

Waring, R. H. and Schlesinger, W. H.: Forest ecosystems concepts and management, Academic Press, New York, 69 pp., 1985.

Webster, R. and Oliver, M. A.: Geostatistics for environmental scientists, Wiley, Chichester, 2001.

Xu, X. J., Zhou, G. M., Liu, S. G., Du, H. Q., Mo, L. M., Shi, Y. J., Jiang, H., Zhou, Y. F., and Liu, E. B.: Implications of ice storm damages on the water and carbon cycle of bamboo forests in southeastern China, Agr. Forest Meteorol., 177, 35-45, 2013. 
Yuan, W. G., Shen, A. H., Jiang, B., Zhu, J. R., and Lu, G.: Study on litterfall characteristics of evergreen broadleaf forest in Zhejiang, J. Zhejiang For. Tech., 29, 1-4, 2009 (in Chinese).

Zhang, C. S., Luo, L., Xu, W., and Ledwith, V.: Use of local Moran's $\mathrm{I}$ and GIS to identify pollution hotspots of $\mathrm{Pb}$ in urban soils of Galway, Ireland, Sci. Total Environ., 398, 212-221, 2008.

Zhang, F., Du, Q., Ge, H. L., Liu, A. X., Fu, W. J., and Ji, B. Y.: Spatial distribution of forest carbon in Zhejiang Province with geostatistics based on CFI sample plots, Acta Ecol. Sin., 32, 52755286, 2012 (in Chinese).
Zhang, X. Y., Sui, Y. Y., Zhang, X. D., Meng, K., and Herbert, S. J.: Spatial variability of nutrient properties in black soil of northeast China, Pedosphere, 17, 19-29, 2007.

Zhejiang Forestry Bureau, Forest resources in Zhejiang Province, Chinese Agricultural and Technological Press, 5-9, 2006 (in Chinese).

Zhou, X. N., Wu, Z. L., Zheng, L. F., Cai, R. T., Luo, J. H., and Lin, H. M.: Biomass and nutrient content of forest litter in natural forest of different intensity harvesting after ten years, Sci. Silvae Sinicar, 44, 25-28, 2008 (in Chinese). 